Z. Klin. Chem. Klin. Biochem.

12. Jg. 1974 , S. $344-349$

\title{
Eine Methode zur direkten Bestimmung des Creatinins in Serum und Harn ohne Enteiweißung nach einer modifizierten Jaffé-Methode
}

\author{
Von R. Helger, H. Rindfrey und J. Hilgenfeldt
}

Aus der Biochemischen Abteilung der E. Merck, Darmstadt und dem Klinisch-Chemischen Institut (Direktor: Prof. Dr. Dr. V. Klingmüller) Klinikum Mannheim der Universität Heidelberg

(Eingegangen am 6. Februar/3. April 1974)

Es wird über eine Methode zur Bestimmung von Creatinin in Serum und Harn mit alkalischer Pikratlösung (Jaffé-Reaktion) ohne Enteiweißung berichtet. Der störende Einfluß von Nebenreaktionen wurde durch Optimierung der wichtigsten Test-Parameter weitgehend ausgeschlossen. Die Bestimmung kann mit einem Testsatz sowohl manuell als auch an mechanisierten Analysensystemen, die den Reaktionsverlauf registrieren, wie z. B. dem LKB 8600 Reaction Rate Analyzer, durchgeführt werden. Die Brauchbarkeit der Methode wurde in einem klinischen Labor bestätigt.

\section{A method for the direct estimation of creatinine in serum and urine}

A method is described for the determination of creatinine in serum and urine based on the picrate reaction under alkaline conditions (Jaffé), but without deproteinisation. Interference by side-reactions has been largely excluded by optimizing the main assay parameters. The determination can be performed with a manual test kit, or with an automatic kinetic measuring device like the LKB 8600 Reaction Rate Analyzer. The utility of the method was proved in a clinical laboratory.

Die Creatininbestimmung in Serum und Harn gilt als der wichtigste Suchtest auf eine eingeschränkte Nierenfunktion bei Niereninsuffizienz, die durch eine Retention harnpflichtiger Substanzen gekennzeichnet ist. Zur Bestimmung des Creatinins wird im allgemeinen die Reaktion mit Pikrinsäure im alkalischen Milieu unter Bildung eines orange-gelben Farbstoffes, der photometrisch bestimmbar ist, herangezogen. Die von Jaffé (1) zuerst beschriebene Methode liefert in der Regel zu hohe Werte, da außer Creatinin noch sogenannte Jaffé-positive Substanzen miterfaßt werden. Die wichtigsten dieser Pseudo-Creatinin-Chromogene sind Acetessigsäure, Pyruvat, Glucose, Ascorbinsäure, Aceton und Glycocyamidin. Diesen Nachteil versuchte man schon vielfach durch verschiedene Modifikationen der Methode zu umgehen.

Zur spezifischen Adsorption von Creatinin und damit zur Abtrennung von störenden Substanzen wurde bisher meistens Lloyds-Reagenz (Fuller-Erde) verwendet $(2,3)$. In den letzten Jahren wurden ar.ch Methoden zur selektiven Adsorption von Creatinin an organischen Ionenaustauschern beschrieben'(4). Diese Methoden besitzen zwar eine hohe Spezifität, sind aber technisch aufwendig und sowohl für Einzelbestimmungen als auch für grössere Serien in der Routine nur beschränkt geeignet. Einen gewissen Einfluß auf die Spezifität hat die Art der Enteiweißung; man erhält deutlich niedrigere Resultate nach Dialyse, doch können auch hierdurch niedermolekulare Störsubstanzen, wie Acetessigsäure, nicht eliminiert werden (5). In vielen Arbeiten wurde versucht, durch die Wahl optimaler Reaktionsbedingungen (z. B. Pikrinsäurekonzentration, pH-Wert und Reaktionszeit) Verbesserungen zu erzielen, doch scheint erst mit enzymatischen Methoden ein Weg zur absolut spezifischen Bestimmung des Creatinins gefunden worden zu sein $(6,7)$. Für die Routine wird aber die Jaffé-Reaktion weiterhin Bedeutung behalten und es erschien gerechtfertigt, nach neuen Möglichkeiten zu suchen, deren Spezifität zu erhöhen und die Methodik beispielsweise durch Verzicht auf eine Enteiweißung zu vereinfachen.

Den ersten Veröffentlichungen von Grisler und Castelnuovo (8) und von Bartels und Boehmer (9) folgten sehr bald weitere Arbeiten (10-19), in welchen Methoden zur Creatininbestimmung ohne Enteiweißung beschrieben wurden. Durch drastische Verringerung der seither üblichen Pikrinsäurekonzentration im Ansatz konnte die irreversible Ausfällung von Eiweiß vermieden werden. Da die Serumproben jetżt nicht mehr durch ein Fällungsmittel verdünnt werden, wird eine beachtliche Empfindlichkeitssteigerung erzielt bzw. wird weniger Serum zur Analyse bènötigt. Aufbauend auf den von Bartels et al (20-23) durchgeführten Untersuchungen wurde eine 
Methode für die direkte Creatininbestimmung ausgearbeitet, die sowohl die manuelle Durchführung kleiner Analysenserien wie auch die Verwendung mechanisierter Analysensysteme erlaubt. Verschiedene Parameter wurden optimiert und die Brauchbarkeit der Methode im praktischen Einsatz nachgewiesen.

\section{Methodik}

Reagenzien

a) für die manuelle Bestimmung

(Merckotest Creatinin, E. Merck Nr. 3385)

1. Pufferlösung: $\mathrm{NaOH}, 313 \mathrm{mmol} / \mathrm{l} ; \mathrm{Na}_{2} \mathrm{HPO}_{4}, 12,5 \mathrm{mmol} / 1$

2. Pikrinsäure, $8,73 \mathrm{mmol} / 1$;

3. Standardlösung: Creatinin, $88,4 \mu \mathrm{mol} / 1$ $10 \mathrm{mmol} / 1$ Salzsäure

b) für die mechanisierte Bestimmung

(Merckotest Automatenpackung Creatinin, E. Merck Nr. 3384)
4. Pufferlösung: $\mathrm{NaOH}, 1,565 \mathrm{~mol} / \mathrm{l}$; $\mathrm{Na}_{2} \mathrm{HPO}_{4}, 62,5 \mathrm{mmol} / 1$
5. Pikrinsäure, $4,37 \mathrm{mmol} / 1$

c) für die Technicon Autoanalyzer-Methode

6. Natriumchlorid-Brij-Lösung (E. Merck Nr. 9407) $(\mathrm{NaCl}, 154 \mathrm{mmol} / \mathrm{l})$

7. Pikrinsäurelösung (E. Merck Nr. 10478) $\left(\mathrm{C}_{6} \mathrm{H}_{3} \mathrm{~N}_{3} \mathrm{O}_{7}, 52,4 \mathrm{mmol} / 1\right)$

8. Natronlauge (E. Merck Nr. 9144) $(\mathrm{NaOH}, 500 \mathrm{mmol} / \mathrm{l})$

\section{Haltbarkeit}

Alle Lösungen sind verschlossen aufbewahrt bei $15^{\circ}$ bis $25^{\circ} \mathrm{C}$ 1 Jahr haltbar.

Geräte

Spektrallinien-Filterphotometer Eppendorf, Meßwellenlänge $492 \mathrm{~nm}$;

LKB-Reaction-Rate-Analyzer 8600 , Filter $500 \mathrm{~nm}$;

Technicon Autoanalyzer, 1. Generation

Durchführung der Versuche

\section{Manuelle Bestimmung}

Die Reaktion ist sehr temperaturempfindlich. Deshalb müssen die Pufferlösung (1) und die Pikrinsäure (2) exakt vortemperiert werden; die Reaktion muß bei konstant gehaltener Temperatur ablaufen. Insbesondere muß die Reaktionstemperatur des Standards und der Analysen identisch sein. Wenn diese Bedingungen erfullt sind, kann bei beliebigen Temperaturen $\mathrm{zwischen}$ $20^{\circ}$ und $37^{\circ} \mathrm{C}$ gearbeitet werden. $\mathrm{Zu}$ jeder Analysenserie werden ein bis zwei Standards angẹsetžt. In Reagenzgläser werden pipettiert:

$\begin{array}{ll}\text { Analyse } & \text { Standard } \\ 0,5 \mathrm{ml} & \overline{0,5} \mathrm{ml} \\ \overline{1}, 0 \mathrm{ml} & 1,0 \mathrm{ml}\end{array}$

Serum oder $1+99$ verd. Harn

Standardlösung (3)

Pikrinsäure (2)

Mischen, etwa $5 \mathrm{~min}$ temperieren.

Pufferlösung (1) $\quad 1,0 \mathrm{ml} \quad 1,0 \mathrm{ml}$

Mischen, sofort in die Küvette gießen, innerhalb von $1 \mathrm{~min}$, Extinktion $E_{1}$ und genau 5 min nach der ersten Messung Extinktion $E_{2}$ messen (Wellenlänge $492 \mathrm{~nm}$, Schichtdicke $1 \mathrm{~cm}$ ); Analyse und Standard müssen identisch behandelt werden. Bei Reaktionstemperaturen über $30^{\circ} \mathrm{C}$ muß die Extinktion $E_{1}$ innerhalb von $30 \mathrm{~s}$ gemessen werden. Bei Werten über $442 \mu \mathrm{mol} / 1 \mathrm{Cre}-$ atinin (50 mg/1 Creatinin) Serum oder $1+99$ verd. Harn wird die Bestimmung mit der $1+5$ mit physiologischer Natriumchloridlösung verdünnten Probe wiederholt und das Ergebnis mit 6 multipliziert.

Die Berechnung erfolgt nach folgender Formel:

Serum-Creatinin-Konzentration $=\frac{E_{A_{2}}-E_{A_{1}}}{E_{S_{2}}-E_{S_{1}}} \cdot 88,4 \mu \mathrm{mol} / 1$

$\left(E_{A}=\right.$ Extinktion der Analyse, $E_{S}=$ Extinktion des Standards $)$. Die Berechnungsformel für die Harn-Creatinin-Konzentration unterscheidet sich hiervon durch die zusätzliche Multiplikation mit dem Verdünnungsfaktor 100.

Mechanisierte Bestimmung am LKB-Reaction Rate Analyzer 8600 Geräteeinstellung (vgl. auch Bedienungsanleitung des Herstellers): Filter 490 oder $500 \mathrm{~nm}$, Reaktionsverlauf increase, Hintergrundblende OA (operate), Einspritzdüse weiß, Dosiervolumen $100 \mu \mathrm{l}$, Registrierbereich 0,200, Meßzeit pro Probe $1 \mathrm{~min}$, Papiervorschub $60 \mathrm{~mm} / \mathrm{min}$.

Analysenschema (zu jeder Analysenserie werden 2 bis 3 Standards angesetzt):

$\begin{array}{rc}\text { Analyse } & \text { Standard } \\ -\quad 200 \mu \mathrm{l} \\ 200 \mu \mathrm{l} & - \\ 1000 \mu \mathrm{l} & 1000 \mu \mathrm{l}\end{array}$

Standardlösung ( 3 )

Serum oder $1+99$ verd. Harn

Pikrinsäurelösung (4)

$15 \mathrm{~min}$ bei $35^{\circ} \mathrm{C}$ vorinkubieren.

Pufferlösung (5)

$100 \mu \mathrm{l} \quad 100 \mu \mathrm{l}$

Mischen und Reaktionsverlauf messen. Bei Werten über $844 \mu \mathrm{mol} / \mathrm{l}$ (100 mg/l Creatinin) wird die Bestimmung mit der $1+5 \mathrm{mit}$ physiologischer Natriumchloridlösung verdünnten Probe wiederholt und das Ergebnis mit 6 multipliziert. Zur Berechnung ermittelt man aus den Reaktionskurven $\Delta \mathrm{E}_{\mathrm{S}} / \mathrm{min}$ bzw. $\Delta \mathrm{E}_{\mathrm{A}} / \mathrm{min}$ und setzt diese Werte in die folgende Formel ein:

Serum-Creatinin-Konzentration $=\frac{\Delta E_{A} / \mathrm{min}}{\Delta E_{S} / \min } \cdot 88,4 \mu \mathrm{mol} / 1$

$\left(E_{A}=\right.$ Extinktion der Analyse, $E_{S}=$ Extinktion des Standards $)$. Zur Berechnung der Harn-Creatinin-Konzentration vgl. manuelle Bestimmung.

Bestimmung am Technicon Autoanalyzer

Entsprechend der Technicon-Methodology N-11 b, 60 Proben/

Stunde, Berechnung über eine Standard-Bezugskurve.

\section{Ergebnisse}

Die Umsetzung von Creatinin mit Pikrinsäure, aber auch die Bildung der Pseudo-Creatinin-Chromogene, ist stark von der Alkalikonzentration im Testansatz abhängig. Bei der Umsetzung von Creatinin-Standardlösungen $(88,4$ $\mu \mathrm{mol} / 1,0,5 \mathrm{ml}$ ) bzw. von Humanseren mit Pikrinsäurelösung $(5,67 \mathrm{mmol} / 1,1,0 \mathrm{ml})$ und Natronlauge $(1,0 \mathrm{ml})$ unterschiedlicher Konzentration nimmt mit steigender Alkalikonzentration die Meßempfindlichkeit (Extinktionsdifferenz pro 10 Minuten) zu und erreicht bei etwa $400 \mathrm{mmol} / 1$ Alkali ein Maximum (Tab. 1). Ein gleiches Verhalten zeigen die Serumproben, jedoch setzt bei höheren Alkalikonzentrationen nach relativ kurzer Zeit eine Zweitreaktion ein, die zu einem schnellen Extinktionsanstieg führt (Abb. 1 und 2). Diese Zweitreaktion kann verhindert werden, wenn die Alkalikonzentration $400 \mathrm{mmol} / 1$ nicht übersteigt. 
Tab. 1. Abhängigkeit der Reaktion einer wäßrigen, salzsauren Creatinin-Standardlösung $(88,4 \mu \mathrm{mol} / 1,0,5 \mathrm{ml}) \mathrm{bzw}$. von Serum $(0,5 \mathrm{ml})$ mit Pikrinsäure $(5,67 \mathrm{mmol} / 1,1,0 \mathrm{ml})$ und Natronlauge $(1,0 \mathrm{ml})$ von der Konzentration der Natronlauge.

\begin{tabular}{llr}
\hline NaOH-Konzentration & \multicolumn{2}{c}{$\Delta \mathrm{E}_{492} / 10 \mathrm{~min}$ bei $30^{\circ} \mathrm{C}$} \\
mmol/1 & Standard & Serum \\
\hline 100 & 0,077 & 0,060 \\
200 & 0,110 & 0,110 \\
400 & 0,123 & 0,145 \\
500 & 0,103 & 0,120 \\
\hline
\end{tabular}

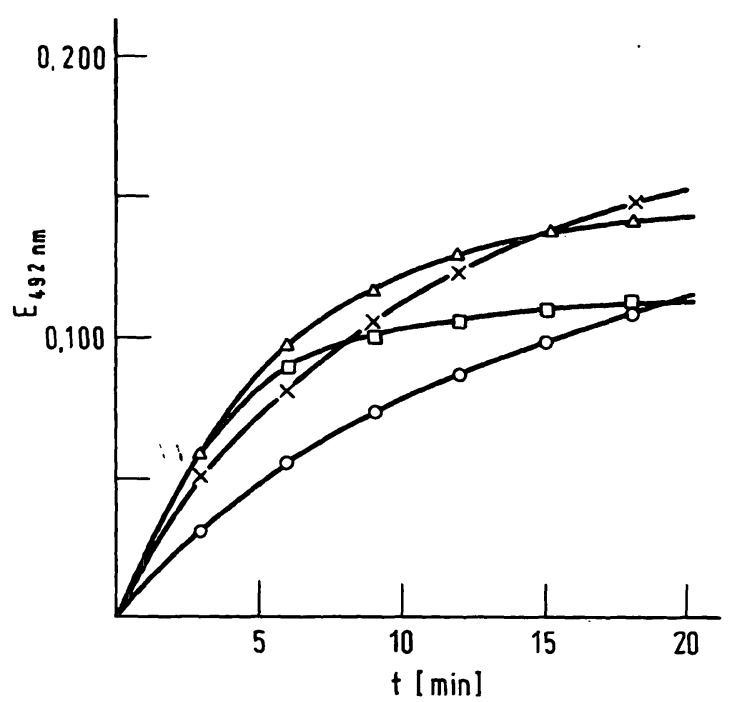

Abb. 1. Reaktionsverlauf der Umsetzung einer Creatinin-Standardlösung $(88,4 \mu \mathrm{mol} / 1 ; 0,5 \mathrm{ml})$ mit Pikrinsäurelösung $(5,67 \mathrm{mmol} / 1 ; 1,0 \mathrm{ml})$ und Natronlauge $(1,0 \mathrm{ml})$ unterschiedlicher Konzentration.

$$
\begin{aligned}
& 0=100 \mathrm{mmol} / \mathrm{l}, \quad X=200 \mathrm{mmol} / \mathrm{l}, \\
& \Delta=400 \mathrm{mmol} / 1, \quad \square=500 \mathrm{mmol} / 1 \mathrm{Natriumhydroxid}-
\end{aligned}
$$

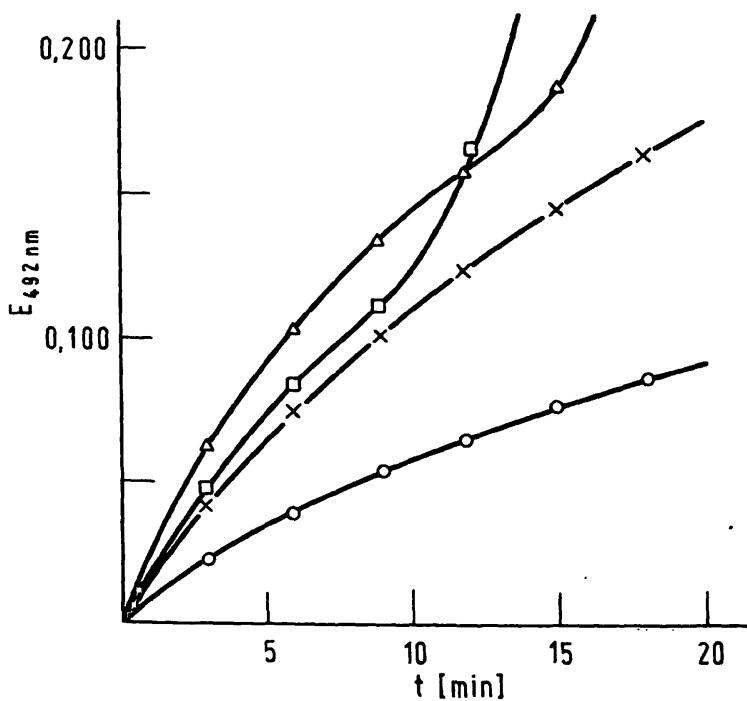

Abb. 2. Reaktionsverlauf der Umsetzung von Humanserum $(0,5 \mathrm{ml})$ mit Pikrinsäurelösung $(5,67 \mathrm{mmol} / 1 ; 1,0 \mathrm{ml})$ und Natronlauge $(1,0 \mathrm{ml})$ unterschiedlicher Konzentration.

$0=100 \mathrm{mmol} / 1$, $\Delta=400 \mathrm{mmol} / \mathrm{l}$,

$X=200 \mathrm{mmol} / \mathrm{l}$

$\mathrm{\sigma}=500 \mathrm{mmol} / 1 \mathrm{Natriumhydroxid}$ lösung
Tab. 2. Abhängigkeit der Reaktion einer wäßrigen, salzsauren Creatinin-Standardlösung $(88,4 \mu \mathrm{mol} / 1,0,5 \mathrm{ml}) \mathrm{bzw}$. von Serum $(0,5 \mathrm{ml}) \mathrm{mit}$ Natronlauge $(500 \mathrm{mmol} / 1$, $1,0 \mathrm{ml})$ und Pikrinsäure $(1,0 \mathrm{ml})$ von der Konzentration der Pikrinsäurelösung.

\begin{tabular}{lll}
\hline $\begin{array}{l}\text { Pikrinsäurekonzen- } \\
\text { tration } \\
\text { mmol/1 }\end{array}$ & \multicolumn{2}{c}{$\Delta \mathrm{E}_{492} / 10 \mathrm{~min}$ bei $30^{\circ} \mathrm{C}$} \\
\hline 4,36 & Standardlösung & Serum \\
5,67 & 0,113 & 0,120 \\
8,72 & 0,120 & 0,147 \\
17,46 & 0,118 & 0,165 \\
26,19 & 0,100 & 0,187 \\
\hline
\end{tabular}

Die Meßempfindlichkeit kann auch durch die Wahl der Pikrinsäurekonzentration beeinflußt werden. Tabelle 2 zeigt die Abhängigkeit der Reaktion von CreatininStandardlösungen $(88,4 \mu \mathrm{mol} / 1,0,5 \mathrm{ml})$ und von Humanseren $(0,5 \mathrm{ml})$ mit Natronlauge $(500 \mathrm{mmol} / 1,1,0 \mathrm{ml})$ und Pikrinsäurelösung $(1,0 \mathrm{ml})$ unterschiedlicher Konzentration. Bei den Ansätzen mit den Standardlösungen nähert sich die Extinktionsdifferenz pro 10 Minuten mit steigender Pikrinsäurekonzentration einem Maximum und nimmt dann wieder ab. Bei den analogen Ansätzen mit Serum werden mit żunehmender Pikrinsäurekonzentration jeweils steigende Extinktionsdifferenzen gemessen, die Meßempfindlichkeit durchläuft kein Maximum. Die Zweitreaktion wird durch die Veränderung der Pikrinsäurekonzentration nicht beeinflußt (Abb. 3).

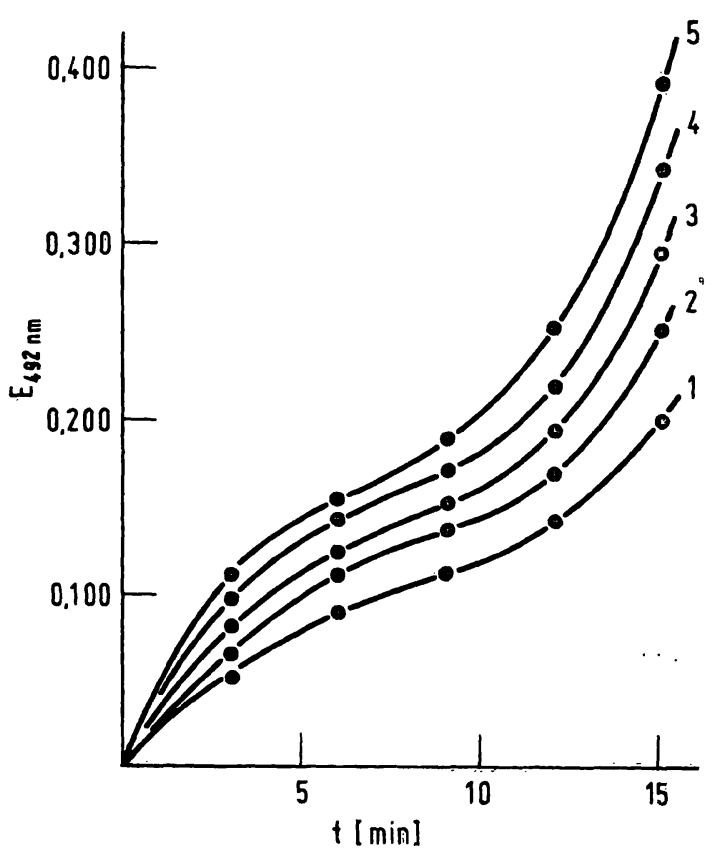

Abb. 3. Reaktionsverlauf der Umsetzung von Humanserum $(0,5$ $\mathrm{ml}) \mathrm{mit}$ Natronlauge $(500 \mathrm{mmol} / \mathrm{l} ; 1,0 \mathrm{ml})$ und Pikrinsäurelösung. $(1,0 \mathrm{ml})$ unterschiedlicher Konzentration.
$(1)=4,36 \mathrm{mmol} / \mathrm{l}$,
(2) $=5,67 \mathrm{mmol} / 1$
(3) $=8,72 \mathrm{mmol} / 1$
(4) $=17,46 \mathrm{mmol} / \mathrm{l}$
(5) = 26,19 mmol/1 Pikrinsäurelösung

Z. Klin. Chem. Klin. Biochem. / 12. Jahrg. 1974 / Heft 7 
Unter Zusammenfassung aller Versuchsergebnisse fanden wir beim genannten Ansatz optimale Bedịngungen bei Zugabe einer $\mathrm{NaOH}$-Lösung mit einer Konzentration zwischen 200 und $300 \mathrm{mmol} / \mathrm{l}$ und Zugabe einer Pikrinsäurelösung mit einer Konzentration zwischen 17,5 und $26 \mathrm{mmol} / \mathrm{l}$. Bei den Serumansätzen werden aber bereits bei einer Pikrinsäurekonzentraiton von mehr als $9 \mathrm{mmol} / \mathrm{l}$ geringe Mengen Protein ausgefallt. Diese lösen sich zwar nach Zugabe der $\mathrm{NaOH}$-Lösung wieder, aber die Temperierung und das Mischen des Testansatzes bereiten Schwierigkeiten. Besonders die Verwendung dieser Methode an mechanisierten Analysensystemen, bei welchen ein intensives Mischen nicht immer gewährleistet ist, legte nahe, eine Pikrinsäurekonzentration von $9 \mathrm{mmol} / 1$ nicht zu überschreiten. Um möglichst weitgehend diese Einflüsse zu berücksichtigen, arbeiten wir abweichend zur Methode von Bartels et al. (20-23) mit folgenden Endkonzentrationen im Test (Werte nach (20) in Klammern): $\mathrm{NaOH}, 125$ (200) mmol/1; Pikrinsäure, $3,5(2,3) \mathrm{mmol} / 1$.

Aufgrund der Abhängigkeit der Creatinin-PikrinsäureReaktion von der Alkalikonzentration muß bei der Jaffé-Methode streng darauf geachtet werden, daß Proben und Standard bei gleichem $\mathrm{pH}$-Wert reagieren (24, 16). In besonderem Maß gilt dies bei der direkten Creatinin-Bestimmung, da Serum-Eiweiß als Puffer wirkt. Um eine ähnliche Pufferwirkung im Standard zu erzielen, wurde die Verwendung einer mit Glycin/ $\mathrm{NaOH}$ gepufferten Standardlösung vorgeschlagen (20), die aber nur kurze Zeit haltbar ist. Ausreichende Stabilität kann nur erreicht werden, wenn Creatinin in Säure gelöst wird. Um aber auch hier in den Standard- und Serumansätzen gleiche $\mathrm{pH}-$ Werte zu erhalten, wird dem Testansatz Phosphat in einer Konzentration von $5 \mathrm{mmol} / \mathrm{l}$ zugesetzt.

Unter den beschriebenen Bedingungen verläuft die Reaktion von Creatinin mit Pikrinsäure in Natronlauge in wäßrigen Standardlösungen und in Serumproben identisch. Die bei der Methode nach Bartels et al (20) in den Serumansätzen auftretende Zweitreaktion konnte ausgeschaltet werden (vgl. Abb. 4). Dadurch ist es möglich, Creatinin ohne gleichzeitige Erfassung von Pseudo-Creati: nin-Chromogenen im Serum direkt zu bestimmen.

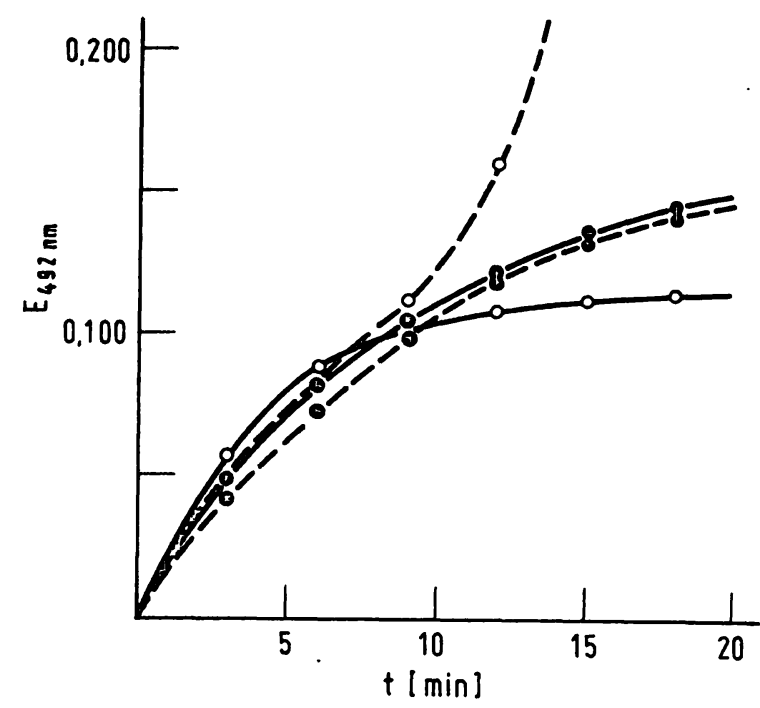

Abb. 4. Reaktionsverlauf der Umsetzung von Creatinin-Standardlösungen (durchgezogene Linie) und von Humanseren (gestrichelte Linie) nach der hier beschriebenen

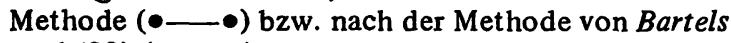
et al (20) (0-0).

Die unter Methodik beschriebene Arbeitsanleitung berücksichtigt die bisher erläuterten Ergebnisse. Zum Nachweis der Brauchbarkeit in der Routine wurde Creatinin in 702 Seren und 184 Harnen auf dem LKB-Reaction Rate Analyzer 8600, sowie in 222 Seren und 63 Harnen manuell mit dem Photometer Eppendorf bestimmt. Als Vergleichsmethode diente die Creatininbestimmungmit dem Technicon Autoanalyzer. Die Creatininkonzentrationen der untersuchten Seren lagen zwischen 44,2 und $1856 \mu \mathrm{mol} / 1$ ( 5 und $210 \mathrm{mg} / \mathrm{l})$, die der Harne zwischen 2,12 und 29,3 mmol/1. Die Ergebnisse sind in den Tabellen 3 und 4 zusammengefaßt. Die Korrelation der mit dem Technicon Autoanalyzer und dem LKB Gerät bzw. manuell ermittelten Werte ist sehr gut. Erwartungsgemäß liegen die Werte der neuen Methode ohne Enteiweißung etwa 5 bis $15 \%$ niedriger als nach der Technicon Autoanalyzer-Methode. Die Verdünnung der Proben bei Konzentrationen über $442 \mu \mathrm{mol} / \mathrm{l}$ führt gegenüber unverdünnten Proben zu höheren Ergebnissen. Die Präzision von Tag zu Tag wurde an verschiedenen Kontrollseren ermittelt, die Ergebnisse sind in Tabelle 5

Tab. 3. Vergleich der Ergebnisse nach der Technicon Autoanalyzer-Methode und nach der beschriebenen Methode am LKB-Reaction Rate Analyzer 8600 (LKB)

\begin{tabular}{|c|c|c|c|c|c|c|c|c|}
\hline & $\mathbf{N}$ & $\begin{array}{l}\bar{x} \text { (Auto- } \\
\text { analyzer) } \\
{[\mu \mathrm{mol} / 1]}\end{array}$ & $\begin{array}{l}s \text { (Auto- } \\
\text { analyzer) } \\
{[\mu \mathrm{mol} / 1]}\end{array}$ & $\begin{array}{l}\overline{\mathbf{x}} \text { (LKB- } \\
\text { Analyzer) } \\
{[\mu \mathrm{mol} / 1]}\end{array}$ & $\begin{array}{l}\text { s (LKB- } \\
\text { Analyzer) } \\
{[\mu \mathrm{mol} / 1]}\end{array}$ & $\mathbf{r}$ & $y=a+b x$ & $\begin{array}{l}\text { Syx } \\
{[\mu \mathrm{mol} / 1]}\end{array}$ \\
\hline Serumwerte & 702 & 259 & 292 & 233 & 279 & 0,930 & $\begin{aligned} y= & 3,71+ \\
& 0,953 x\end{aligned}$ & 107 \\
\hline $\begin{array}{l}\text { Werte über } \\
442 \mu \mathrm{mol} / 1 \\
\text { (unverdünnt) }\end{array}$ & 69 & 866 & 253 & 819 & 271 & 0,902 & $\begin{aligned} y= & 31,0+ \\
& 0,878 x\end{aligned}$ & 114 \\
\hline $\begin{array}{l}\text { Werte über } \\
442 \mu \mathrm{mol} / 1 \text { (verdünnt) }\end{array}$ & 69. & 866 & 253 & 861 & 259 & 0,875 & $\begin{aligned} y= & 116+ \\
& 0,841 x\end{aligned}$ & 128 \\
\hline Harnwerte & 184 & 108. & 54,8 & 105 & 51,3 & 0,923 & $\begin{aligned} y= & 12,6+ \\
& 0,864 x\end{aligned}$ & 20 \\
\hline
\end{tabular}


Tab. 4. Vergleich der Ergebnisse nach der Technicon-Autoanalyzer-Methode und nach der beschriebenen Methode manuell mit dem Spektrallinien-Filterphotometer

\begin{tabular}{|c|c|c|c|c|c|c|c|c|}
\hline & $\mathbf{N}$ & $\begin{array}{l}\overline{\mathrm{x}} \text { (Auto- } \\
\text { analyzer) } \\
{[\mu \mathrm{mol} / 1]}\end{array}$ & $\begin{array}{l}\text { s (Auto- } \\
\text { analyzer) } \\
{[\mu \mathrm{mol} / 1]}\end{array}$ & $\begin{array}{l}\overline{\mathrm{x}}(\text { Eppen- } \\
\text { dorf Photo- } \\
\text { meter) } \\
{[\mu \mathrm{mol} / 1]}\end{array}$ & $\begin{array}{l}s \text { (Eppen- } \\
\text { dorf Photo- } \\
\text { meter) } \\
{[\mu \mathrm{mol} / 1]}\end{array}$ & $\mathbf{r}$ & $y=a+b x$ & $\begin{array}{l}\text { Syx } \\
{[\mu \mathrm{mol} / 1]}\end{array}$ \\
\hline Serumwerte & 222 & 301 & 301 & 268 & 298 & 0,987 & $\begin{aligned} y= & 32,3+ \\
& 0,988 x\end{aligned}$ & 45,9 \\
\hline Harnwerte & 63 & 118 & 51,3 & 103 & 44,2 & 0,952 & $\begin{aligned} y= & 8,75+ \\
& 0,792 x\end{aligned}$ & 13,0 \\
\hline
\end{tabular}

Tab. 5. Daten zur Präzision der beschriebenen Methode von Tag zu Tag. Mittelwert, Standardabweichung und Variationskoeffizient in Kontrollseren am LKB-Reaction Rate Analyzer 8600 (LKB) bzw. manuell mit dem Spektrallinien-Filterphotometer (Ep)

\begin{tabular}{|c|c|c|c|c|c|c|c|c|c|c|}
\hline & $\begin{array}{l}\text { Qualtrol } \\
\text { LKB }\end{array}$ & $\begin{array}{l}\text { Labtrol } \\
\text { LKB }\end{array}$ & $\mathrm{Ep}$ & $\begin{array}{l}\text { Pathotrc } \\
\text { LKB }\end{array}$ & Ep & $\begin{array}{l}\text { Monitrol IX } \\
\text { LKB }\end{array}$ & $\begin{array}{l}\text { Monitrol I } \\
\text { LKB }\end{array}$ & $\begin{array}{l}\text { Monitrol II } \\
\text { LKB }\end{array}$ & $\begin{array}{l}\text { Urinko } \\
\text { LKB }\end{array}$ & $\begin{array}{l}\text { trolle } \\
\text { Ep }\end{array}$ \\
\hline $\begin{array}{l}N \\
\bar{x} \\
(\mu \mathrm{mol} / 1)\end{array}$ & $\begin{array}{l}25 \\
84\end{array}$ & $\begin{array}{l}29 \\
87,5\end{array}$ & $\begin{array}{l}25 \\
81,3\end{array}$ & $\begin{array}{r}31 \\
115\end{array}$ & $\begin{array}{r}20 \\
103\end{array}$ & $\begin{array}{r}20 \\
115\end{array}$ & $\begin{array}{r}23 \\
116\end{array}$ & $\begin{array}{r}24 \\
312\end{array}$ & $\begin{array}{l}20 \\
61,9\end{array}$ & $\begin{array}{l}20 \\
62,8\end{array}$ \\
\hline SK \% & $\begin{array}{l}4,42 \\
5,26\end{array}$ & $\begin{array}{l}3,54 \\
4,0\end{array}$ & $\begin{array}{l}3,54 \\
4,35\end{array}$ & $\begin{array}{l}3,54 \\
3,1\end{array}$ & $\begin{array}{l}4,42 \\
4,29\end{array}$ & $\begin{array}{l}5,30 \\
4,61\end{array}$ & $\begin{array}{l}7,1 \\
6,1\end{array}$ & $\begin{array}{r}11,5 \\
3,68\end{array}$ & $\begin{array}{l}3,54 \\
5,71\end{array}$ & $\begin{array}{l}1,77 \\
2,82\end{array}$ \\
\hline
\end{tabular}

Kontrollseren Qualtrol, Labtrol, Pathotrol, Monitrol der Firma Merz und Dade; Urinkontrolle der Firma Hyland.

zusammengefaßt. Bei Creatininkonzentrationen um $90 \mu \mathrm{mol} / \mathrm{l}$ liegt der Variationskoeffizient bei $5 \%$, wobei zwischen manueller und mechanisierter Durchführung nur geringe Differenzen bestehen. Der Normalbereich im Serum lag bei der Bestimmung mit dem LKB-Reaction Rate Analyzer zwischen 45 und $109 \mu \mathrm{mol} / 1$ (5,1 und $12,3 \mathrm{mg} / \mathrm{l})(\mathrm{N}=355, \overline{\mathrm{x}}=77 \mu \mathrm{mol} / 1 \mathrm{bzw} .8,7 \mathrm{mg} / \mathrm{l})$. Eine Differenzierung nach Männern und Frauen wurde nicht durchgefüht, trotzdem ist erkennbar, daß die Werte für Serum deutlich niedriger liegen als die von Dubach et al (25) für die Technicon Autoanalyzer-Methode mitgeteilten Normalbereiche im Serum für Männer $\overline{\mathrm{x}}=$ $105 \mu \mathrm{mol} / 1(11,9 \mathrm{mg} / \mathrm{l}) \mathrm{bzw}$. für Frauen $\overline{\mathrm{x}}=84,9 \mu \mathrm{mol} / 1$ $(9,6 \mathrm{mg} / 1)$.

\section{Diskussion}

Die vorliegende Methode für die Creatininbestimmung ohne Enteiweißung hat den Vorteil, daß infolge der geringen Pikrinsäurekonzentration die Messung im Extinktionsmaximum erfolgen kann und eine Eiweißfällung ausbleibt. Später einsetzende Nebenreaktionen haben wegen des schnellen Reaktionsablaufes zwischen Creatinin und der alkalischen Pikratlösung keinen Einfluß auf das Meßergebnis. Diese Modifikation der JafféReaktion zeichnet sich deshalb durch eine höhere Spezifität aus. Bei der angewandten Methode ist die Reaktionsgeschwindigkeit ein Maß für die Berechnung der Creatininkonzentration, d. h. es erfolgt je eine Extinktionsmessung zu Beginn und während der laufenden Reaktion. Da die Aktivierungsenergie der Jaffé-Reaktion äußerst niedrig ist, muß man darauf achten, unter möglichst standardisierten Bedingungen zu arbeiten. Die Temperatur und die Meßzeit müssen genau eingehalten werden. Aus diesem Grund ist die Durchführung der Creatininbestimmung mit mechanisierten Analysensystemen, z. B. mit dem LKB-Reaction Rate Analyzer 8600, besonders einfach. Große Analysenserien können ohne großen Arbeitsaufwand durchgeführt werden. Beim Arbeiten mit dem LKB-Gerät sind nur 2 Pipettierungen, Serum und Pikrinsäure, notwendig. Die Reaktion wird durch automatische Zugabe der Pufferlösung gestartet. Es genügt das Mitfuihren eines Standards in jeder Serie. Eine Verdünnung der Probe ist anders als bei der manuellen Durchfuihrung erst bei einer Creatininkonzentration von mehr als $900 \mu \mathrm{mol} / 1$ (etwa $100 \mathrm{mg} / \mathrm{l}$ ) erforderlich. Die Korrelation der mit dem Technicon Autoanalyzer und dem LKB-Gerät ermittelten Werte ist mit $r=0,93$ sehr eng.

Die beschriebene manuelle Durchführung der Creatininbestimmung mit einem Spektrallinien-Filterphotometer eignet sich sehr gut für das kleine und mittlere Laboratorium, wo nur kleine Analysenserien anfallen. Größere Serien lassen sich nach dieser Methode manuell nicht rationell durchführen, da der Arbeitsaufwand zu groß ist. Der Wegfall der Enteiweißung bedeutet jedoch eine wesentliche Erleichterung. Es muß aber auch hier besonders darauf geachtet werden, daß die Reaktionszeiten und die Temperaturen von Standard und Proben identisch sind. Durch die Verwendung von Einmalküvetten wird die Vorbereitung der Analyse und das Einhalten der Reaktionszeit erleichtert.

Der Vergleich der in Seren manuell gefundenen Ergebnisse mit den Technicon Autoanalyzer-Werten ergibt mit $r=0,987$ eine sehr enge Korrelation. Der Normalbereich fựr Seren bei Männern von 62 bis $106 \mu \mathrm{mol} / 1$ ( 7 bis $12 \mathrm{mg} / \mathrm{l}$ ) und bei Frauen von 44 bis $88 \mu \mathrm{mol} / 1$ ( 5 bis $10 \mathrm{mg} / \mathrm{l}$ ) konnte bestätigt werden. 


\section{Literatur}

1. Jaffé, M. (1886), Hoppe-Seyler's'Z. Physiol. Chem. 10, $391-400$

2. Knoll, E. \& Stamm, D. (1970), diese Z. 8, 582-587.

3. Owen, I. A., Iggo, B., Scandrett, F. J. \& Stewart, C. P. (1954), Biochem. J. 58, 426-437

4. Rockerbie, R. A. \& Rasmussen, K. L. (1967), Clin. Chim. Acta 15, 475-479.

5. Watkins, P. J. (1967), Clin. chim. Acta 18, 191-196.

6. McLean, M. H. \& Gallwas, I. (1972), Scand. J. Clin. Lab. Invest. 29, Suppl. 126

7. Wahlefeld, A. W., Herz, G. \& Bergmeyer, H. U. (1972), Scand. J. Clin. Lab. Invest. 29, Suppl. 126.

8. Grisler, R. \& Castelnuovo, E. (1970), Quad. Sclavo Diagn. 6, 473-478.

9. Bartels, H. \& Böhmer, M. (1971), Clin. Chim. Acta 32, $81-85$.

10. Blennemann, H. (1971), Ärztl. Lab. 17, 363-368.

11. Cook, I. G. H. (1971), Clin. Chim. Acta. 32, 485-486.

12. Fabiny, D. L. \& Ertinghausen, G. (1971), Clin. Chem. 17, 696-700.

13. Haury, H. (1972), Diagnostik 5, 226-229.

14. Heinegard, D. \& Tiderström, G. (1973), Clin. Chim. Acta $43,305-310$.

15. Larsen, K. (1972), Clin. Chim. Acta 38, 475-476.

16. Larsen, K. (1972), Clin. Chim. Acta 41, 209-217.

17. Raabo, E. \& Wallöe-Hansen, P. (1972), Scand. J. Clin. Lab. Invest. 29, 297-301.

18. Zender, R. \& Jacot, P. (1972), Anal. Lett. 5, 143-152.

19. Knoll, E. \& Wisser, H. (1973), diese Z. 11, 411-414.

20. Bartels, H., Böhrner, M. \& Heierli, C. (1972), Clin. Chim. Acta 37, 193-197.

21. Bartels, H. (1972), Chemische Rundschau 25, 501-503.

22. Heierli, Ch., Thölen, H. \& Bartels, H. (1972), Deut. Med. Wochenschr. 97, 67-70.

23. Bartels, H. (1973), Med. Laborat. 26, 209-215.

24. Bartels, H. \& Cikes, M. (1969), Clin. Chim. Acta 26, 1-10.

25. Dubach, U. C., Merz, I. \& Schmid, P. (1967), Klin. Wochenschr. 45, 621-628.
Dr. R. Helger

Biochem. Abt. E. Merck 6100 Darmstadt Postfach 